\title{
Reliability of respiratory pressure measurements in ventilated and non-ventilated patients in ICU: an observational study
}

\author{
Clément Medrinal ${ }^{1,2,3^{*}}$, Guillaume Prieur ${ }^{4}$, Yann Combret ${ }^{5,6}$, Aurora Robledo Quesada ${ }^{3}$, Tristan Bonnevie ${ }^{1,2,7}$, \\ Francis Edouard Gravier ${ }^{7}$, Eric Frenoy ${ }^{8}$, Olivier Contal ${ }^{9}$ and Bouchra Lamia ${ }^{1,2,4,10}$
}

\begin{abstract}
Background: Assessment of maximum respiratory pressures is a common practice in intensive care because it can predict the success of weaning from ventilation. However, the reliability of measurements through an intubation catheter has not been compared with standard measurements. The aim of this study was to compare maximum respiratory pressures measured through an intubation catheter with the same measurements using a standard mouthpiece in extubated patients.
\end{abstract}

Methods: A prospective observational study was carried out in adults who had been under ventilation for at least $24 \mathrm{~h}$ and for whom extubation was planned. Maximal respiratory pressure measurements were carried out before and $24 \mathrm{~h}$ following extubation.

Results: Ninety patients were included in the analyses (median age: 61.5 years, median SAPS2 score: 42.5 and median duration of ventilation: 7 days). Maximum respiratory pressures measured through the intubation catheter were as reliable as measurements through a standard mouthpiece (difference in maximal inspiratory pressure: mean bias $=-2.43 \pm 14.43 \mathrm{cmH}_{2} \mathrm{O}$ and difference in maximal expiratory pressure: mean bias $=1.54 \pm 23.2 \mathrm{cmH}_{2} \mathrm{O}$ ).

Conclusion: Maximum respiratory pressures measured through an intubation catheter were reliable and similar to standard measures.

Clinical trial registration Retrospectively Registered in ClinicalTrials.gov (NCT02363231).

Keywords: Intensive care unit, Mechanical ventilation, Respiratory muscles

\section{Background}

Mechanical ventilation generally results in a loss of respiratory muscle strength $[1,2]$. The prevalence of respiratory muscle weakness is high, and the causes are multifactorial [3-5]. Assessment of respiratory muscle strength is becoming common practice in intensive care. Assessment techniques range from diaphragm ultrasound to measurement of maximum respiratory pressures. Respiratory muscle strength has been established as prognostic of successful weaning and mortality [6-8].

\footnotetext{
*Correspondence: medrinal.clement.mk@gmail.com

${ }^{3}$ Intensive Care Unit Department, Groupe Hospitalier du Havre, Avenue Pierre Mendes France, 76290 Montivilliers, France

Full list of author information is available at the end of the article
}

Measurement of maximum respiratory pressures is a simple, non-invasive method to quantify the global strength of the inspiratory and expiratory muscles. Pressures can be measured using a manometer with a unidirectional valve or the "Negative Inspiratory Force" (NIF) function available on most ventilators. However, these methods require full patient cooperation. Several protocols have thus been developed for use in intensive care to ensure accurate measurements with or without cooperation from the patient [9]. Several studies have attempted to determine optimal methods to ensure quality measurements that are reliable [10-12].

Respiratory pressure measurements are commonly carried out, while the patient is intubated as part of the evaluation to determine the likely success of extubation [5, 
7]. It is important to carry out longitudinal evaluations of respiratory muscle strength after mechanical ventilation in order to increase understanding of the relationship between strength and long-term rates of mortality [7]. However, the methods used to measure respiratory pressures differ between intubation and extubation and, along with other factors such as lack of patient cooperation and discomfort, this could lead to different values being recorded. To our knowledge, no, or few, studies have evaluated respiratory pressure measurements in non-ventilated patients in ICU, and the reliability of these measurements has not been compared between intubation and extubation.

The aim of this study was to compare maximum respiratory pressures measured through an intubation catheter (intubated patients) with the same measurement using a standard mouthpiece (extubated patients). The secondary aims were to analyse correlations between the two measurements.

\section{Method}

\section{Study design and participants}

This study was part of a larger, prospective observational cohort study conducted in an 18-bed intensive care unit (ICU) between January 2014 and December 2014 [7]. The study was approved by our Institutional Review Board (Comité de Protection des Personnes Nord-Ouest 3); NCT02363231 www.clinicaltrials.gov. In conformity with the Declaration of Helsinki, all patients participated voluntarily.

Patients were included if they were over 18 years of age and had undergone a minimum of $24 \mathrm{~h}$ of MV. They were not included if they had chronic loss of autonomy (a KATZ score below 6/6 [13], a degenerative neurological pathology with disabling muscle weakness, were agitated prior to the evaluation (Ramsay score of 1 or Richmond Agitation-Sedation Scale (RASS) greater than 1) or a decision to withhold life sustaining treatment had been made. Patients who were included but had to be re-intubated during the first $24 \mathrm{~h}$ of extubation were excluded from the analysis.

\section{Study protocol}

In our ICU, patients are assessed daily (without sedation) to determine whether they are ready to wean from MV. If a patient fulfils extubation criteria and level of cooperation is satisfactory, a weaning trial is carried out under pressure support (inspiratory positive airway pressure of $7 \mathrm{cmH}_{2} \mathrm{O}$ with no expiratory positive airway pressure for 30-120 min) [14]. For the purpose of the study, if the trial was successful and extubation was planned, the patient underwent maximum inspiratory and expiratory pressure measurements (MIPs and MEPs) (intubation condition). Twenty-four hours following extubation, MIPs and MEPs were re-measured, this time using a mouthpiece (mouthpiece condition).

Demographic data, reasons for admission to ICU and comorbidities were collected at the time of inclusion, prior to carrying out the MIP and MEP measurements under MV.

In both conditions, the MIP and MEP measurements were carried out with the patient lying in bed with the backrest inclined to $45^{\circ}$. Respiratory physiotherapy was carried out first to ensure that secretions were evacuated, and endotracheal aspiration was carried out for intubated patients.

An electronic manometer, micro-RPM ${ }^{\circledR}$ (Eolys, PAYS), with a unidirectional valve was used to measure respiratory pressures. In both conditions, MIP was measured at the residual volume and patients were instructed accordingly.

In the intubation condition, the manometer was connected to the endotracheal tube using a catheter mount. The patient was disconnected from the ventilator for a minimum of $20 \mathrm{~s}$ [11].

In the mouthpiece condition, it was not possible to leave the manometer in position for $20 \mathrm{~s}$. MIP was measured after a maximal exhalation (at the residual volume).

MEP was measured after a maximal inspiration in both conditions. Three MIP and three MEP measurements were carried out for each patient, and the best result was used for the analysis.

\section{Statistical analysis}

Descriptive statistics are reported as counts and percentages for categorical data, and means and standard deviations or medians and 25th-75th percentiles for continuous variables, depending on the normality of the distribution. Differences between values were evaluated using a Wilcoxon matched-pairs signed rank test. Univariate linear regression analysis was performed using the least squares method. The Bland-Altman limits of agreement method was used to calculate bias and precision.

Statistical analyses were performed using GraphPad Prism 5. A two-tailed $p$ value of 0.05 was considered significant for all analyses.

\section{Results}

One hundred and twenty-four patients were included in the larger study. Of these, 101 accepted to carry out additional measurements. Eleven patients required reintubation within $24 \mathrm{~h}$ of extubation and were excluded from the analysis. Ninety patients thus underwent MIP and MEP measurements in both conditions. 
Patient characteristics are described in Table 1. Briefly, $43 \%$ of the patients were women, median age was 61.5 years, median BMI was $28.6 \mathrm{~kg} / \mathrm{m}^{2}$, median SAPS2 score was 42.5 and median duration of $\mathrm{MV}$ was 7 days.

Median MIP value was $28(21.7-40.2) \mathrm{cmH}_{2} \mathrm{O}$ in the intubation condition and $27(19-38) \mathrm{cmH}_{2} \mathrm{O}$ in the mouthpiece condition $(p=0.02)$. Linear regression showed a significant correlation between the values in each condition $(r=0.6495 \%$ CI [0.5-0.75]; $p<0.0001)$.

The Bland-Altman analysis showed that the MIP values between intubation and extubation were clinically comparable (mean bias $(\Delta \mathrm{MIP})=-2.43 \pm 14.43$ $\mathrm{cmH}_{2} \mathrm{O}$ ). (See Fig. 1).

There was no statistically significant difference in MEP values between conditions [47 (30-74) vs. 53.5 (34-76.2) $\left.\mathrm{cmH}_{2} \mathrm{O} ; p=0.2\right]$. There was a strong significant correlation between the MEP values in each condition $(r=0.71$ 95\% CI [0.6-0.8]; $p<0.0001)$.

There was no clinical difference between the values in the two conditions as shown by the Bland-Altman analysis $\left(\right.$ mean bias $\left.(\triangle \mathrm{MEP})=1.54 \pm 23.2 \mathrm{cmH}_{2} \mathrm{O}\right)(\mathrm{See}$ Fig. 2).

No patient-related factors were found to be associated with the measurement bias (age, BMI, SAPS2, number of days under mechanical ventilation, extubation failure). However, there was a correlation between the $\triangle \mathrm{MIP}$ and the $\Delta \mathrm{MEP}(r=0.4995 \%$ CI $[0.31-0.64] ; p<0.0001)$.

There was a significant correlation between MIP and MEP values in each condition (respectively $r=0.6195 \%$ CI $[0.45-0.72] ; p<0.0001$ and $r=0.66$ 95\% CI [0.52$0.77] ; p<0.0001)$.

\section{Discussion}

This study found [1] that the methods of measuring respiratory pressures in intubated and extubated patients produced clinically similar results for both MIP and MEP, and [2] there were strong correlations between the MIP and MEP values in both conditions.

Assessment of respiratory pressures is common practice in ICU [4, 5, 7, 9-12]. Although other tools may more accurately assess muscle strength, measures of respiratory pressure are used to determine if a patient is ready to wean from MV, as well as the prognosis [7, 15]. For this reason, we believed it was important to evaluate the validity of measurements in intubated patients compared with post-extubation measurements using a mouthpiece in order to longitudinally evaluate changes in respiratory muscle strength.

Measurement of maximal respiratory pressures requires patient cooperation, which can be difficult when patients are intubated; however, similar pressures were recorded during intubation and extubation, with slightly higher pressures during intubation. This could
Table 1 Cohort characteristics

\begin{tabular}{|c|c|}
\hline & $N=90$ \\
\hline Female, $n(\%)$ & $39(43)$ \\
\hline Age, mean (SD) & $61.5(14)$ \\
\hline Body mass index $\left(\mathrm{Kg} / \mathrm{m}^{2}\right)$, median (25th-75th percentile) & $28.6(24.4-32)$ \\
\hline SAPS II at ICU admission, median (25th-75th percentile) & $42.5(31-57)$ \\
\hline No. of admissions to ICU within the last year, $n(\%)$ & $4(4.4)$ \\
\hline \multicolumn{2}{|l|}{ Main diagnosis } \\
\hline Pneumonia, $n(\%)$ & $32(35)$ \\
\hline Sepsis, $n(\%)$ & $8(9)$ \\
\hline COPD/asthma exacerbation, $n(\%)$ & $12(13)$ \\
\hline Cardiac failure, $n(\%)$ & $12(13)$ \\
\hline Drug overdose/acute mental status change, $n(\%)$ & $11(12)$ \\
\hline Intra-abdominal sepsis with surgery, n (\%) & $14(15)$ \\
\hline Trauma, $n(\%)$ & $1(4)$ \\
\hline \multicolumn{2}{|l|}{ Co-morbidity } \\
\hline Chronic pulmonary disease, $n(\%)$ & $23(25)$ \\
\hline Obesity, $n(\%)$ & $27(30)$ \\
\hline Chronic cardiac insufficiency, $n$ (\%) & $13(14)$ \\
\hline Cancer, $n(\%)$ & $15(17)$ \\
\hline Chronic kidney disease, $n$ (\%) & $14(15)$ \\
\hline Diabetes mellitus, $n(\%)$ & $17(19)$ \\
\hline \multicolumn{2}{|l|}{ Between admission and awakening } \\
\hline Septic shock, $n(\%)$ & $45(50)$ \\
\hline ARDS, $n(\%)$ & $13(14)$ \\
\hline Renal failure, $n(\%)$ & $30(33)$ \\
\hline Use of catecholamines, $n(\%)$ & $58(64)$ \\
\hline Use of neuromuscular blockers, $n(\%)$ & $58(64)$ \\
\hline $\begin{array}{l}\text { No. of days of neuromuscular blockers, median ( } 25-75 \text { th } \\
\text { percentile) }\end{array}$ & $1(0-3)$ \\
\hline Use of corticosteroids, $n(\%)$ & $21(78)$ \\
\hline Ventilator use (days), median (25th-75th percentile) & $7(4-9)$ \\
\hline
\end{tabular}

SAPS simplified acute physiology score, ICU intensive care unit, No. number, COPD chronic obstructive pulmonary disease, ARDS acute respiratory distress syndrome

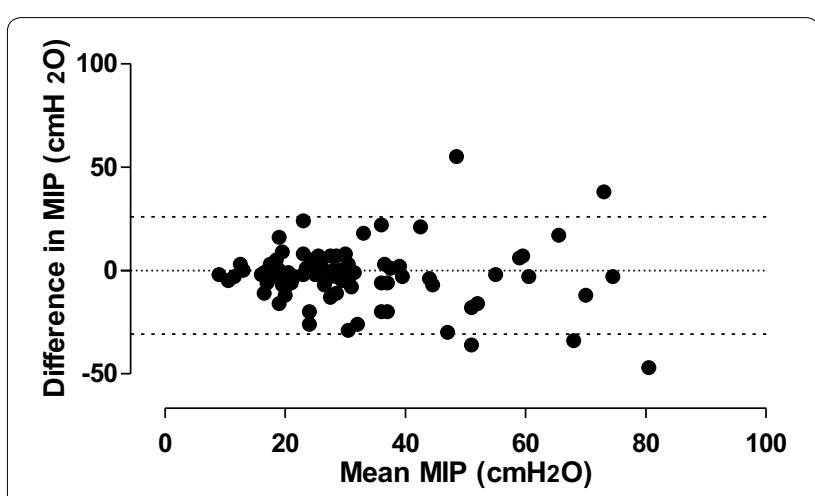

Fig. 1 Bland-Altman analysis of maximal inspiratory pressure correlations: difference versus mean 


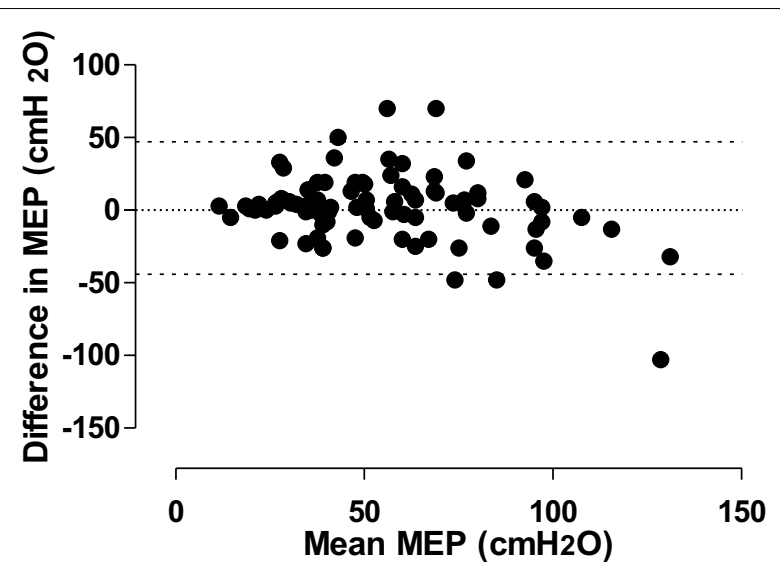

Fig. 2 Bland-Altman analysis of maximal expiratory pressure correlations: difference versus mean

be explained by the fact that mouth leak cannot occur when the patient is intubated with the balloon inflated or because the measurement was carried out over $20 \mathrm{~s}$ when the patients were intubated [11]. One study compared the conventional method (values taken at the maximum pressure plateau maintained for at least $1 \mathrm{~s}$ ) with Marini's method [10] (measurement of inspiratory pressure with a unidirectional valve over $20 \mathrm{~s}$ ) in 54 patients. MIP was $28 \%$ higher using Marini's method with a coefficient of variation of around $10 \%$, indicating good reliability. This procedure can be used for intubated patients but is not reliable in extubated patients. Nevertheless, in the present study, mean MIP variation between the two conditions was $-2.43 \mathrm{cmH}_{2} \mathrm{O}(-8.4 \%)$ and for MEP was 1.54 $\mathrm{cmH}_{2} \mathrm{O}(7 \%)$, confirming good reliability across conditions and measurements.

The results of this study showed a relationship between MIP and MEP. MEP reflects the patient's capacity to cough, and a low MEP is associated with delayed weaning [15]; however, studies tend to focus on inspiratory muscle strength, neglecting expiratory muscle strength. MIP is reported to be predictive of successful extubation, and we recently showed that low MIP before extubation $\left(\mathrm{MIP} \leq 30 \mathrm{cmH}_{2} \mathrm{O}\right)$ was an independent predictor of an increase in mortality risk 1 year following extubation [7]. However, several authors have stated that values obtained in intubated patients may be underestimated [9, 12, 15]. In the current study, we found that Marini's method (occlusion for $20 \mathrm{~s}$ ) produced clinically similar values to measurements carried out with a mouthpiece following recommendations [16]. This indicates that if the patient is sufficiently alert, the values are not underestimated and are therefore reliable across different conditions, allowing accurate follow-up of respiratory capacity.
This study has several limitations. Firstly, the observational design comprises several types of inherent bias and we did not perform a sample size calculation. Secondly, it was not possible to evaluate patients who were re-intubated within $24 \mathrm{~h}$. Thirdly, the pressure measurements were not taken in exactly the same conditions. The second measurement $24 \mathrm{~h}$ following extubation may have been affected by respiratory muscle fatigue. Finally, we evaluated peak pressure, not pressure maintained over $1 \mathrm{~s}$ as recommended [16]. However, the recommendations are more relevant out of ICU where measurements of respiratory pressure differ considerably from the bedside measurements used in ICU [11].

This study has several strengths. The sample size was large and representative of the population of patients in ICU. The test evaluated is simple and easy to carry out at the patient's bedside. Moreover, we showed that the measurements were reliable across two common conditions in ICU (intubated and extubated patients).

\section{Conclusion}

Respiratory pressure measurements are reliable in both intubated and non-intubated patients. These results corroborate those of previous studies. Measurements of respiratory pressure can thus be carried out reliably when the patient is intubated and repeated following weaning from MV to carry out longitudinal evaluations of respiratory muscle recovery.

\section{Abbreviations}

BMI: body mass index; Cl: confidence intervals; ICU: intensive care unit; MIP: maximal inspiratory pressure; MEP: maximal expiratory pressure; MV: mechanical ventilation; NIF: negative inspiratory force; RASS: Richmond AgitationSedation Scale; SAPS: simplified acute physiology score.

\section{Author's contributions}

C.M., G.P., Y.C., O.C and B.L. designed the study. C.M., B.L. and O.C. coordinated the study. C.M., G.P., E.F., A.R.Q., T.B and F.G. were responsible for patient screening, enrolment, diaphragm assessment, and follow-up. C.M., E.F. O.C. and B.L. analysed the data and wrote the manuscript. All authors contributed to the interpretation of the data and provided comments on the report at various stages of development. All authors approved this manuscript in its final form.

\section{Author details}

${ }^{1}$ Normandie Univ, UNIROUEN, EA3830 - GRHV, 76000 Rouen, France. ${ }^{2}$ Institute for Research and Innovation in Biomedicine (IRIB), 76000 Rouen, France.

${ }^{3}$ Intensive Care Unit Department, Groupe Hospitalier du Havre, Avenue Pierre Mendes France, 76290 Montivilliers, France. ${ }^{4}$ Pulmonology Department, Groupe Hospitalier du Havre, Avenue Pierre Mendes France, 76290 Montivilliers, France. ${ }^{5}$ Institut de Recherche Expérimentale et Clinique (IREC), Pôle de Pneumologie, ORL and Dermatologie, Université Catholique de Louvain, Brussels 1200, Belgium. ${ }^{6}$ Physiotherapy Department, Groupe Hospitalier du Havre, Avenue Pierre Mendes France, 76290 Montivilliers, France. ${ }^{7}$ ADIR Association, Bois Guillaume, France. ${ }^{8}$ Intensive Care Unit Department, Hôpital Jacques Monod, 76290 Montivilliers, France. ${ }^{9}$ University of Applied Sciences and Arts Western Switzerland (HES-SO), Avenue de Beaumont, 1011 Lausanne, Switzerland. ${ }^{10}$ Intensive Care Unit, Respiratory Department, Rouen University Hospital, Rouen, France. 


\section{Competing interests}

The authors declare that they have no competing interests.

\section{Availability of data and materials}

The dataset supporting the conclusions of this article is included within the article.

\section{Consent for publication}

All patients or their relatives provided informed consent to participate.

\section{Ethics approval}

Ethical approval was granted by the French Comité de Protection des Personnes Nord-Ouest 3 (A13-D42-VOL.18).

\section{Funding}

This study was supported by grants from ADIR Association. The funder had no direct influence on the design of the study, the analysis of the data, the data collection, drafting of the manuscript or the decision to publish.

\section{Publisher's Note}

Springer Nature remains neutral with regard to jurisdictional claims in published maps and institutional affiliations.

Received: 25 October 2017 Accepted: 23 January 2018

Published online: 30 January 2018

\section{References}

1. Levine S, Nguyen T, Taylor N, Friscia ME, Budak MT, Rothenberg P, et al. Rapid disuse atrophy of diaphragm fibers in mechanically ventilated humans. N Engl J Med. 2008;358(13):1327-35.

2. Demoule A, Molinari N, Jung B, Prodanovic H, Chanques G, Matecki S, et al. Patterns of diaphragm function in critically ill patients receiving prolonged mechanical ventilation: a prospective longitudinal study. Ann Intensive Care. 2016;6(1):75.

3. Dres M, Dube BP, Mayaux J, Delemazure J, Reuter D, Brochard L, et al. coexistence and impact of limb muscle and diaphragm weakness at time of liberation from mechanical ventilation in medical intensive care unit patients. Am J Respir Crit Care Med. 2017;195(1):57-66.
4. Medrinal C, Prieur G, Frenoy E, Combret Y, Gravier FE, Bonnevie T, et al. Is overlap of respiratory and limb muscle weakness at weaning from mechanical ventilation associated with poorer outcomes? Intensive Care Med. 2017:43(2):282-3.

5. Jung B, Moury PH, Mahul M, de Jong A, Galia F, Prades A, et al. Diaphragmatic dysfunction in patients with ICU-acquired weakness and its impact on extubation failure. Intensive Care Med. 2016:42(5):853-61.

6. Demoule A, Jung B, Prodanovic H, Molinari N, Chanques G, Coirault C, et al. Diaphragm dysfunction on admission to the intensive care unit. Prevalence, risk factors, and prognostic impact-a prospective study. Am J Respir Crit Care Med. 2013:188(2):213-9.

7. Medrinal C, Prieur G, Frenoy E, Robledo Quesada A, Poncet A, Bonnevie T, et al. Respiratory weakness after mechanical ventilation is associated with one-year mortality—a prospective study. Crit Care. 2016;20(1):231.

8. Zambon M, Greco M, Bocchino S, Cabrini L, Beccaria PF, Zangrillo A. Assessment of diaphragmatic dysfunction in the critically ill patient with ultrasound: a systematic review. Intensive Care Med. 2017;43(1):29-38.

9. Moxham J, Goldstone J. Assessment of respiratory muscle strength in the intensive care unit. Eur Respir J. 1994;7(11):2057-61.

10. Marini JJ, Smith TC, Lamb V. Estimation of inspiratory muscle strength in mechanically ventilated patients: the measurement of maximum inspiratory pressure. J Crit Care. 1986:1(1):32-8.

11. Caruso P, Friedrich C, Denari SD, Ruiz SA, Deheinzelin D. The unidirectional valve is the best method to determine maximum inspiratory pressure during weaning. Chest. 1999;115(4):1096-101.

12. Spadaro S, Marangoni E, Ragazzi R, Mojoli F, Verri M, Longo L, et al. A methodological approach for determination of maximum inspiratory pressure in patients undergoing invasive mechanical ventilation. Minerva Anestesiol. 2015:81(1):33-8.

13. Katz S, Akpom CA. A measure of primary sociobiological functions. Int $J$ Health Serv. 1976;6(3):493-508.

14. Boles JM, Bion J, Connors A, Herridge M, Marsh B, Melot C, et al. Weaning from mechanical ventilation. Eur Respir J. 2007:29(5):1033-56.

15. De Jonghe B, Bastuji-Garin S, Durand MC, Malissin I, Rodrigues P, Cerf C, et al. Respiratory weakness is associated with limb weakness and delayed weaning in critical illness. Crit Care Med. 2007;35(9):2007-15.

16. ATS/ERS Statement on respiratory muscle testing. Am J Respir Crit Care Med. 2002:166(4):518-624.

\section{Submit your manuscript to a SpringerOpen ${ }^{\odot}$ journal and benefit from:}

- Convenient online submission

- Rigorous peer review

- Open access: articles freely available online

- High visibility within the field

Retaining the copyright to your article

Submit your next manuscript at $\boldsymbol{\nabla}$ springeropen.com 